\title{
EDUCAÇÃO AMBIENTAL CRÍTICA E ESTUUDOS DE PATRIMÔNIO CRÍTICO: INTERSECÇÕES E VIRADA PARA PEDAGOGIAS DECOLONIAIS
}

\author{
Bárbara Pelacani ${ }^{1}$ \\ Tiago Silva Alves Muniz ${ }^{2}$ \\ Celso Sánchez ${ }^{3}$
}

Resumo: Este trabalho visa refletir sobre o caráter transversal de abordagens da educação ambiental e patrimonial partindo de sua intersecção voltada para pedagogias decoloniais. Buscamos explorar o aporte da teoria crítica na Educação Ambiental e a necessidade de giro para pedagogias decoloniais construídas coletivamente para "sentipensar". Nesse sentido, ao açambarcar a leitura inter-multi-transdisciplinar entre os diálogos de saberes entendemos que as práticas educativas que contribuem para a formação dos educandos devem promover suporte à autonomia, sustentabilidade, justiça socioambiental e políticas patrimoniais voltadas para a valorização de saberes e práticas que possam ser sustentáveis e viáveis ao grupo envolvido em tais ações educativas.

Palavras-chave: Práticas Educativas, Decolonialidade, Políticas Patrimoniais, Justiça Socioambiental, Filosofia da Educação.

\footnotetext{
1 Doutoranda em Psicossociologia de Comunidades e Ecologia Social (EICOS-UFRJ) - contato: barbara.pelacani@gmail.com

2 Doutorando em Antropologia/Arqueologia no Programa de Pós-Graduação em Antropologia (PPGAUFPA) - contato: tiago_samuniz@yahoo.com.br

${ }^{3}$ Docente do Curso de Graduação e Pós-Graduação em Educação (UNIRIO) e Coordenador do Grupo de Estudos em Educação Ambiental desde el Sur (GEASur) - contato: celso.sanchez@hotmail.com
}

Revbea, São Paulo, V. 14, № 2: 133-151, 2019.

revista brasileira educação ambiental 


\section{Introdução}

O presente artigo visa refletir sobre as ligações entre a Educação Ambiental Crítica e educação patrimonial através de um olhar decolonial, ou seja, dos acúmulos dos estudos que vêm se configurando a partir do giro decolonial. Trata-se de um campo teórico que emerge dos estudos culturais críticos latinoamericanos em diálogo com campos tais como o orientalismo, pós-colonialismo, estudos feministas, que se configuram a partir de outros elementos por apresentar um debate que tem tido penetração nas discussões pedagógicas contemporâneas, em particular, por sua aproximação com os debates anti-racista e multicultural. Nesse sentido, entendemos que as práticas pedagógicas, quando voltadas para conhecimento socialmente útil, mirem para uma educação libertadora visando emancipação dos indivíduos. Com objetivo de identificar interfaces entre a Educação Ambiental e a Educação Patrimonial, este artigo parte de reflexões sobre a colonialidade. Desse modo, analisaremos de modo teórico as práticas educativas, através da chegada do pensamento crítico na Educação Ambiental, assim como a posição do pesquisador/educador frente ao espaço e o "público-alvo" em ações de educação patrimonial. Ao concluir apresentaremos propostas de confluências entre as áreas ambiental e patrimonial ao acompanhar o giro teórico para pedagogias decoloniais.

O ponto de partida para ler, criticamente, nas áreas de educação patrimonial e educação ambiental tem como bases teóricas as obras de Freire (1969); Funari (2001); e Loureiro (2007). Segundo Catherine Walsh (2014), a perspectiva crítica da educação ocupa campo de disputa, demarcado pelas colonialidades do saber, do ser e do poder. Nesse contexto, para entender os aspectos históricos, sociais e econômicos caracterizados pelo modelo dicotômico colonialidade x modernidade, os estudos decoloniais proporcionam via para superar agendas formatadas através de um racismo epistêmico (QUIJANO, 1992). De tal modo, salientamos que as ações pedagógicas ambientais ou patrimoniais devem evidenciar lacunas que foram produzidas com fins de alienação e dominação dos conhecimentos das comunidades que habitam tais territórios em disputa.

Ao abordar temas transversais ou a inter-multi-transdisciplinaridade (WEIL, 1993) pontuamos que alguns tópicos orbitam fora da racionalidade ocidental, de tal forma, acessar as relações existentes entre os eixos social, simbólico e fisicalidade requer uma participação em determinado grupo social a fim de reconhecer práticas e epistemes. Assim, a colaboração de profissionais de áreas distintas pode facilitar o diálogo entre saberes e tal intersecção entre distintas áreas é o interesse desse estudo: averiguar como a decolonialidade pode figurar como uma ponte entre tais deslocamentos teóricos.

O artigo, portanto, está organizado da seguinte forma. Inicialmente, tratamos de alguns conceitos que emergem do campo da decolonialidade para oxigenação das interlocuções com a educação tanto ambiental quanto patrimonial com uma caracterização da educação e do conhecimento no processo de colonialidade. Abordaremos, a seguir, as distintas perspectivas da Revbea, São Paulo, V. 14, No 2: 133-151, 2019. 
Educação Ambiental, inspiradas em conceitos da Justiça Ambiental, como o Racismo Ambiental que invisibiliza saberes ancestrais. No caminho da Educação Patrimonial interpelamos a desumanização e reificação que retiram a liberdade de povos, usurpando e apagando o patrimônio ambiental e cultural dos territórios. As contribuições do campo decolonial aparecem no debate sobre colonizador $x$ colonizado, na busca da ruptura desta dicotomia que se reflete na educação. Identificamos, assim, caminhos possíveis para um ensino que rompa com a lógica colonial, marcando a potência existente da confluência entre Educação Ambiental e Patrimonial.

\section{Do oprimido ao educador: reflexões para uma práxis decolonial}

Conforme posposta por Paulo Freire (1969), a educação concretiza-se pela ação em pensamento e prática, pela práxis, em interação com o outro no mundo. Trata-se de uma dinâmica que envolve a produção e reprodução das relações sociais, reflexão e posicionamento ético na significação política e democrática dos códigos morais de convivência nos processos pedagógicos. Educar pode reproduzir ideais ou também transformar(nos) em seres, em nossas relações no mundo, redefinindo o modo como nos organizamos em sociedade, como gerimos seus instrumentos e como damos sentido às nossas vidas.

A abordagem voltada para açambarcar a alteridade ruma em direção a compreender e respeitar o outro em sua existência, assim como em convivência integrada às demais espécies vivas e em comunhão entre nós, para tais precisamos superar as formas de expropriação que propiciam a dicotomia sociedade $x$ natureza. O predomínio de uma perspectiva ambiental que, ao elidir o humano de ser ambiente, promove relações de poder na qual a dominação legitima processos pedagógicos hegemônicos. Remetendo, portanto, ao seguinte pressuposto: a Educação Ambiental não se refere exclusivamente às relações vistas como naturais ou ecológicas de modo que as sociais fossem a negação direta dessas, recaindo no dualismo, mas sim a todas as relações que nos situam no planeta e que se dão em sociedade dimensão inerente à nossa condição como espécie.

Assim, o educar "ambientalmente" define-se pela unicidade dos processos que problematizam os atributos culturais relativos à vida - quando repensa os valores e comportamentos dos grupos sociais; com os que agem nas esferas política e econômica - quando propicia caminhos sustentáveis e sinaliza para novos padrões societários.

A educação, ao não problematizar os padrões societários ambientais, adota uma postura conservadora (LAYRARGUES, 2004), centrada no indivíduo, no alcançar a condição de ser humano integral e harmônico, pressupondo a existência de finalidades previamente estabelecidas na natureza e de relações ideais. As práticas pedagógicas, ao se eximirem da crítica aos processos em desenvolvimento na sociedade, atenuam as raízes dos problemas ambientais e deixam de lado seu compromisso de 
transformação social. Focalizar 0 ato educativo enquanto mudança de comportamentos compatíveis a um determinado padrão idealizado de relações corretas com a natureza, reproduzindo o dualismo natureza-cultura, com uma tendência a aceitar a ordem social estabelecida como condição dada, sem crítica às suas origens históricas torna-se a base de uma Educação Ambiental conservadora (LOUREIRO, 2006).

De tal maneira, a Educação Ambiental ao problematizar uma perspectiva conservadora de ordem hegemônica, que produz e reproduz práticas e teorias que legitimam poderes estabelecidos na relação sociedade-natureza, gera a reflexão sobre os processos políticos, econômicos e socioambientais em curso. Onde os caminhos traçados podem ser percorridos na busca de uma compreensão das raízes fundantes de tais pedagogias. A partir do diálogo sobre patrimônios material e imaterial, o discurso sobre a decolonialidade emerge como narrativas e desenvolvimento das histórias locais e regionais frente ao processo civilizatório demarcado por uma colonialidade tripartida: a colonialidade do poder, do ser e do saber.

\section{A Educação Ambiental Crítica: A Justiça Ambiental e a Colonialidade da Natureza na construção de perspectivas outras}

A Educação Ambiental é um tema transversal e não uma disciplina, podendo ser inter-multi-transdiciplinar, conforme exposto por Evaristo (2010). A prática de ensino tradicional reforça uma noção de educação bancária, hierarquias, paradigmas, racismos, sexismos, especismos (MUNIZ, 2016). Destarte, a prática de ensino de ciências e respectivas atividades de ensinoaprendizagem revelam como concepções de meio ambiente podem ser avaliadas durante processo pedagógico. Nesta perspectiva, o cotidiano escolar atuando na formação do indivíduo, preenche e é preenchido de significados, já que as visões manifestadas dos educandos sobre a relação entre natureza, humanos e outros animais foram materializadas na pesquisa de Muniz (2016), onde as concepções de meio ambiente de Reigota (1991) foram utilizadas como sistema de interpretação e avaliação ${ }^{4}$.

A relação "natureza vs. cultura/humanidade vs. outros animais" no campo pedagógico tem inúmeras abordagens previstas pelos eixos transversais. O pensamento reducionista criado a partir do paradigma dos animais vistos como seres meramente autômatos, cujas estruturas internas seriam equiparáveis a de um relógio é o que fundamenta o método científico da observação ${ }^{5}$. Entretanto, esta abordagem ignora a visão relacional, na qual se

\footnotetext{
${ }^{4}$ Segundo Reigota (1991) as concepções de meio ambiente podem ser entendidas como: 1) naturalista: meio ambiente como sinônimo de natureza intocada, evidencia-se somente os aspectos naturais; 2) antropocêntrica: evidencia a utilidade dos recursos naturais para a sobrevivência do ser humano; 3) globalizante: relações recíprocas entre natureza e sociedade.

${ }^{5}$ Conforme teoria do animal machine exposta por Descartes (2005).

Revbea, São Paulo, V. 14, № 2: 133-151, 2019.
} 
entende que as coisas e as pessoas estão intimamente imbricadas, emaranhadas.

Para Lévi-Strauss (1982, p.41) "o homem é um ser biológico ao mesmo tempo que social". Sendo essa separação natureza x cultura indissociável, seguindo a abordagem interpretativa, Clifford Geertz resgata em Max Weber a ideia que o ser humano é "um animal amarrado a teias de significados que ele mesmo teceu" (GEERTZ, 1991, p.4). Nesse contexto, destacamos a necessidade de uma abordagem holística dos conhecimentos de comunidades locais frente ao avassalador modelo de conhecimento do mundo moderno, para sentipensar o campo do etnoconhecimento em oposição à noção de modernidade/racionalidade (QUIJANO, 1992) para questionar e romper com a dimensão ontológica da colonialidade (FANON, 2008).

Nessa trama de relações, as relações inter-intra-específicas apontam para uma "questão ambiental" complexa, trans e interdisciplinar. Isso posto, buscamos através da dialética pensar o enredamento do ambiente, a que se propõe a teorizar e agir em processos conexos e integrados, vinculando matéria e pensamento, teoria e prática, corpo e mente. A dialética é o exercício totalizador que nos permite apreender a síntese das determinações múltiplas que conformam a unidade na diversidade, a superação do contraditório pela síntese que estabelece outras contradições, num contínuo movimento de transformação.

A realidade é a síntese entre sujeito e objeto e não algo externo cuja dinâmica é independente de nossa inserção nesta; a verdade se explicita na aplicação prática da teoria e na capacidade de atuarmos reflexivamente em sociedade; a transformação das condições materiais é a norma para a transformação subjetiva - uma sem a outra significa mudanças pontuais e não revoluções substantivas; o sentido da construção do conhecimento e da atuação no mundo é propiciar a emancipação humana e a superação das formas de dissociação sociedade/natureza.

Seguindo raciocínio a partir da complexidade, a finalidade primordial de atuação no campo da Educação Ambiental é transformar os indivíduos em suas subjetividades, sensibilizando práticas para sustentabilidade ambiental e, por conseguinte, manutenção de práticas e saberes imateriais existentes. Em termos concretos, isso significa atuar criticamente na superação das relações sociais vigentes, na conformação de uma ética que possa se afirmar como "ecológica" e na objetivação de um patamar societário que seja a expressão da ruptura com os padrões dominadores que caracterizam a contemporaneidade. Assim posto, privilegiar somente um dos aspectos que formam a nossa espécie, seja a ética, aisthesis, o sensível, comportamental, político, econômico, ecológico ou social é reducionismo. Dessa maneira, estudar o ser humano em sua complexidade contribui para uma visão da educação integradora e sistêmica de mundo. A Educação Ambiental tem como potência cumprir o papel inter-multi-transdiciplinar.

É oportuno recordar também que a "questão ambiental" aqui chegou sob o signo da ditadura militar, com os movimentos Revbea, São Paulo, V. 14, № 2: 133-151, 2019.

revista brasileira educação ambiental 
sociais esfacelados e a educação sob forte repressão, de modo a se evitar a politização dos espaços educativos. $O$ resultado foi, em termos de educação ambiental, uma ação governamental que primava pela dissociação entre o ambiental e o educativo/ político, favorecendo a proliferação dos discursos ingênuos e naturalistas e a prática focada na sensibilização do "humano" perante o "meio natural", ambos desvinculados dos debates sobre modelos societários como um todo. Assim, a educação ambiental ganhou visibilidade como instrumento de finalidade exclusivamente pragmática (em programas e projetos voltados para a resolução de problemas enquadrados como ambientais) e como mecanismo de adequação comportamental ao que genericamente chamou-se de "ecologicamente correto". É por isto, inclusive, que o senso comum muitas vezes acaba vendo a, ainda hoje, como mero meio de apoio em projetos denominados "ambientais", e não como uma perspectiva paradigmática em educação (LOUREIRO, 2004:75-76).

O papel que assume a Educação Ambiental, portanto, é o nome que historicamente se convencionou dar às práticas educativas relacionadas à questão ambiental. Assim, Educação Ambiental designa uma qualidade especial que define uma classe de características que, juntas, permitem o reconhecimento de sua identidade, diante de uma Educação que antes não era ambiental (LAYRARGUES, 2004, p.7). Já, a Educação Ambiental Crítica parte de uma visão sócio histórica para a compreensão da atual crise ambiental a partir das relações sociedade-natureza, para chegar à intervenção social sobre os conflitos ambientais. A Educação Ambiental não é neutra, ela parte de um pensamento epistemológico e filosófico bem demarcado, nem sempre visível quando superficial, que pode ser observado por gerar distintas práticas. No caso da Educação Ambiental Crítica, este é um posicionamento ético-político (CARVALHO, 2004). A epistemologia crítica se baseia na educação com relação intrínseca à superação da totalidade social alienada; na vivência da dialética necessidade / liberdade, indivíduo / sociedade, compreendendo como constitutivos e contraditórios seus movimentos. $O$ autor, nesse sentido, destaca a necessidade de se estar imerso nas lutas sociais dos oprimidos pelo sistema capitalista. Reconhece que "não há respostas prontas, neutralidade científica, soluções prévias e formalistas; mas ação intencional na práxis, no movimento teórico-prático de produção de novos caminhos em nossa história". (LOUREIRO, 2015, p.174).

A Educação Ambiental não se satisfaz com atitudes e mudanças individuais, tais esforços partem de uma visão pragmática neoliberal de particularizar para enfraquecer e culpar os sujeitos pelos danos ambientais, sendo estes então vigiados e punidos. A Educação Ambiental se define como crítica em relação à Educação Ambiental conservadora, que defende os interesses dominantes, agindo de acordo com a lógica do capital, e sendo mais um mecanismo de reprodução desse sistema é incapaz de transformá-lo

Revbea, São Paulo, V. 14, № 2: 133-151, 2019. 
(GUIMARÃES, 2004, p.26). Limitados por uma compreensão de mundo moldada pela racionalidade hegemônica, geram-se práticas incapazes de fazer diferente do "caminho único" prescrito por essa racionalidade, efetivando-se a hegemonia.

Desta forma a Educação Ambiental Conservadora tende, refletindo os paradigmas da sociedade moderna, a privilegiar ou promover: o aspecto cognitivo do processo pedagógico, acreditando que transmitindo o conhecimento correto fará com que o indivíduo compreenda a problemática ambiental e que isso vá transformar seu comportamento e a sociedade; o racionalismo sobre a emoção; sobrepor a teoria à prática; o conhecimento desvinculado da realidade; a disciplinaridade frente à transversalidade; 0 individualismo diante da coletividade; o local descontextualizado do global; a dimensão tecnicista frente à política; entre outros (GUIMARÃES, 2004, p.27).

A Educação Ambiental Crítica é uma contraposição da conservadora em busca de outros objetivos, partindo de outros princípios conceituais e referenciais teóricos, segundo Guimarães (2004) esta é uma abordagem que intenta compreender e intervir na realidade socioambiental através da complexidade mirando o conflito como ponto onde as relações de poder são fundantes na estruturação e múltiplas determinações dos sentidos e dos espaços.

No discurso "harmonioso" feito em nome da salvação planetária, de defesa e afirmação de um "método unificador" das ciências, cria-se a ilusão de que todos os que fazem educação ambiental estão dentro de uma mesma orientação teórico-prática, como se as categorias conceituais que a sustentam - destacadamente participação, interdisciplinaridade, visão integradora do ambiente, respeito à diversidade biológica e cultural - não permitissem diferentes apropriações e usos, dependendo da concepção teórica, do lugar social ocupado pelos sujeitos e da compreensão de sociedade da qual se parta (LOUREIRO, 2006, p.150).

Ao observar os processos socioeconômicos, sob uma perspectiva da Educação Ambiental Crítica, identificamos padrões desiguais de distribuição dos impactos socioambientais no território, caracterizando-se, assim, a existência de conflitos. Nesse sentido, a Educação Ambiental Crítica está em profundo diálogo com o campo da Ecologia Política que se caracteriza por um olhar ampliado da relação sociedade-natureza. É justamente por esse caminho que vamos buscar considerações a partir do que Catherine Walsh vem chamando de Colonialidade da Natureza (2006). Para a autora, este conceito engloba a dualidade na separação natureza sociedade, negando as relações intrínsecas que diversas perspectivas étnicas e culturais desenvolvem com e 
na natureza, numa relação de emaranhamento. Esta perspectiva é a que adotamos para problematizar o campo da Educação Patrimonial, buscando uma confluência com os acúmulos da Educação Ambiental Crítica. Tendo em vista que todo esse debate se alinha com a intenção final de criar condições para a emancipação dos indivíduos.

Sob uma ótica crítica, o conflito socioambiental nos apresenta os problemas distributivos do sistema capitalista e as consequências de modos de vida e formas de conhecimento que se posicionam como hegemônicas. Neste sentido, o movimento da Justiça Ambiental apresenta o conceito de racismo ambiental, no qual aprofunda a compreensão da Educação Ambiental a partir de um olhar para as populações oprimidas. O racismo ambiental contextualiza dentro de tal movimento a dinâmica da relação sociedade-natureza que se impõe a partir da expropriação do direito ao ambiente justo e equilibrado de uma parte determinada da sociedade: as populações vulnerabilizadas.

Chamamos de Racismo Ambiental às injustiças sociais e ambientais que recaem de forma implacável sobre etnias e populações mais vulneráveis. O Racismo Ambiental não se configura apenas através de ações que tenham uma intenção racista, mas, igualmente, através de ações que tenham impacto "racial", não obstante a intenção que Ihes tenha dado origem. (...) O conceito de Racismo Ambiental nos desafia a ampliar nossas visões de mundo e a lutar por um novo paradigma civilizatório, por uma sociedade igualitária e justa, na qual democracia plena e cidadania ativa não sejam direitos de poucos privilegiados, independentemente de cor, origem e etnia" (PACHECO: 2007, s/n).

Segundo Pacheco (2007) a desigualdade demarcada no processo de injustiça ambiental e racismo transcende a cor, pois não se restringe aos negros; ela envolve os trabalhadores latinoamericanos, afro-americanos, afrocaribenhos e asiáticos, assim como as populações tradicionais - ribeirinhos, quebradeiras de coco, marisqueiros, extrativistas, caiçaras e pequenos agricultores familiares - e povos indígenas. O reconhecimento da forma de vida de tais grupos sociais os quais sofrem diretamente o apagamento dos seus saberes e a consequência dos impactos negativos sobre seus territórios, diante do avanço dos grandes empreendimentos de desenvolvimento capitalista, torna-se um dos pontos de interesse da Educação Ambiental Crítica. A cultura e a história integram-se, então, à forma de pensar o ambiente sob outras perspectivas, alargando a visão de mundo para além da delimitação estrita de uma disciplina ou campo de conhecimento. Para tanto, adentramos agora por novos caminhos, em busca de diálogo com a Educação Patrimonial aprofundando o debate rumo ao giro decolonial.

A Educação Ambiental Crítica é aqui apresentada em diálogo com a 
reflexão sobre os processos de desenvolvimento e potência de atuação dos indivíduos enquanto grupos sociais com determinada crítica à Colonialidade da Natureza. Pois, ao integrar saberes, posiciona como ponte entre conhecimentos na compreensão do mundo em que vivemos. O posicionamento aqui apresentado servirá como base para repensar a Educação Ambiental em uma perspectiva decolonial. Para cumprir tal papel, provocamos o encontro com a Educação Patrimonial, buscando caminhos possíveis para um giro na forma hegemônica de pensar e construir conhecimentos pedagógicos.

\section{Educação Patrimonial: da valorização de práticas culturais à sustentabilidade}

A Educação Patrimonial tem como intuito conhecer, divulgar e preservar práticas culturais de ordem material e imaterial. Nesse sentido, ações orientadas por políticas patrimoniais apontam para manutenção de tais práticas culturais que, por exemplo, através da preservação de territórios indígenas tem mostrado sucesso na preservação ambiental e saberes tradicionais ao mesmo tempo. Conforme definido por Horta (1999:4), Educação Patrimonial:

Trata-se de um processo permanente e sistemático de trabalho educacional centrado no Patrimônio Cultural como fonte primária de conhecimento e enriquecimento individual $e$ coletivo. A partir da experiência e do contato direto com as evidências e manifestações da cultura, em todos os seus múltiplos aspectos, sentidos e significados, o trabalho da Educação Patrimonial busca levar as crianças e adultos a um processo ativo de conhecimento, apropriação e valorização de sua herança cultural, capacitando-os para um melhor usufruto destes bens, e propiciando a geração e a produção de novos conhecimentos, num processo contínuo de criação cultural. $\mathrm{O}$ conhecimento crítico e a apropriação consciente pelas comunidades do seu Patrimônio são fatores indispensáveis no processo de preservação sustentável desses bens, assim como no fortalecimento dos sentimentos de identidade $e$ cidadania. A Educação Patrimonial é um instrumento de "alfabetização cultural" que possibilita ao indivíduo fazer a leitura do mundo que o rodeia, levando-o à compreensão do universo sociocultural e da trajetória histórico-temporal em que está inserido. Este processo leva ao reforço da autoestima dos indivíduos e comunidades e à valorização da cultura brasileira, compreendida como múltipla e plural. $\mathrm{O}$ diálogo permanente que está implícito neste processo educacional estimula e facilita a comunicação e a interação entre as comunidades e os agentes responsáveis pela preservação e estudo dos bens culturais, possibilitando a troca de conhecimentos e a formação de parcerias para a proteção e valorização desses bens. A metodologia específica da Educação Patrimonial pode ser aplicada a qualquer evidência material ou manifestação da

revista brasileira educação ambiental 
cultura, seja um objeto ou conjunto de bens, um monumento ou um sítio histórico ou arqueológico, uma paisagem natural, um parque ou uma área de proteção ambiental, um centro histórico urbano ou uma comunidade da área rural, uma manifestação popular de caráter folclórico ou ritual, um processo de produção industrial ou artesanal, tecnologias e saberes populares, e qualquer outra expressão resultante da relação entre os indivíduos e seu meio ambiente. [grifos da autora].

No âmbito escolar, o conceito de patrimônio cultural pode ser abordado como tema transversal a fim de auxiliar os educandos a entender melhor seu espaço e história. De tal maneira, a Educação Patrimonial promove um aprendizado voltado para a memória cultural, despertando nos alunos o interesse de conhecer a identidade local através dos traços do passado. (SOUZA, 2012, p.6). Grande parte das comunidades desconhece a riqueza do patrimônio histórico e arqueológico de seus territórios. De tal maneira, destacase a importância da Educação Patrimonial e suas possibilidades como atividade para estimular a curiosidade científica sobre os primórdios da cultura regional (PACHECO; VARGAS, 2009). Com efeito, encaramos aqui a Educação Patrimonial como proposta voltada para questões pertinentes ao patrimônio ambiental/cultural (Figura 1).
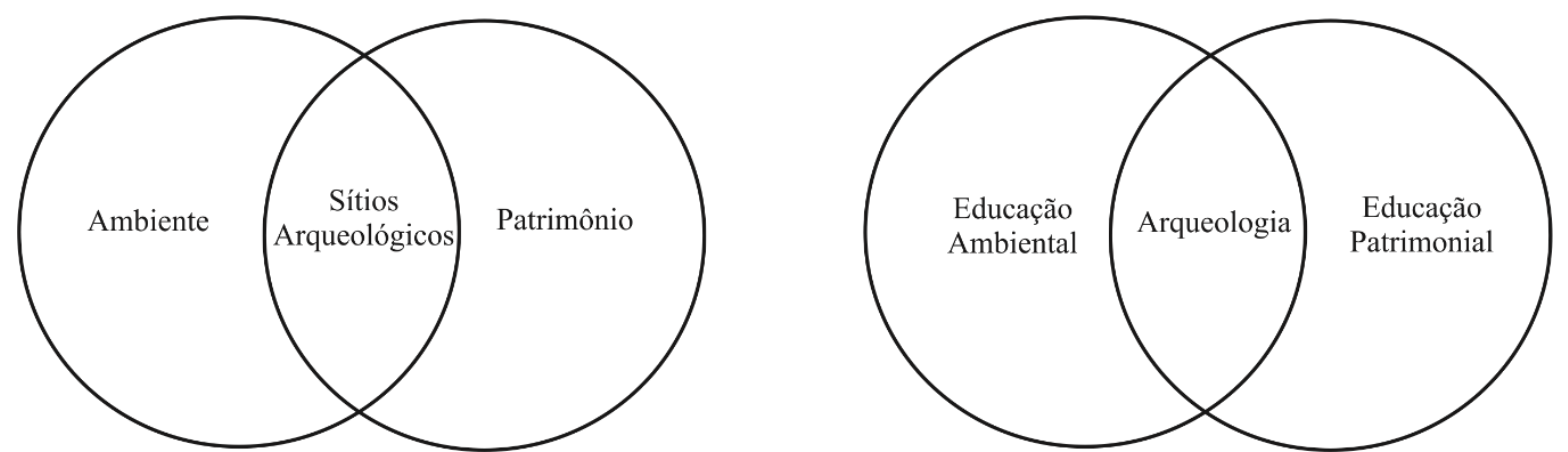

Figura 1: Modelos de relações entre ambiente, patrimônio e abordagens pedagógicas.

Fonte: Adaptado de Pacheco e Vargas (2009).

A escola também contribui para a construção de identidades, uma vez que há o contato do educando com os modos de ser e viver diferentes dos seus e da sua família. O grupo de convívio, as trocas de experiências são vivências que podem marcar por toda vida a forma como ela verá os outros e a si mesma (AQUINO, 2015). Assim, a escola, para o aluno, aparece muitas vezes como um lugar distante, coercitivo e pouco atrativo (ABRAMOVAY, 2002). Papel que se reproduz como observado na relação colonial do ser e do saber na dominação colonizador x colonizado, hierarquizando o conhecimento.

Funari e Pelegrini (2006) indicam que a ênfase no patrimônio brasileiro atinge o seu ápice no período entre 1914 e 1945, quando as duas guerras mundiais eclodem sob o impulso do nacionalismo. A arqueologia tem contribuído de maneira significativa para valorização do patrimônio, ainda que Revbea, São Paulo, V. 14, № 2: 133-151, 2019. 
continue sendo vítima do descaso, do abandono e preservação, não só para proteger, mas, sobretudo, para inserir este patrimônio numa gestão que potencialize a sua vitalidade através da busca de alternativas de atividades econômicas adequadas. Os artefatos, abrigos, edificações e todo o contexto modificado culturalmente pelo homem constituem o conceito de cultura material. Sua análise permite compreender as conquistas e mudanças que os humanos realizaram, ao longo do tempo, em relação à inovação tecnológica e à apropriação dos recursos naturais, no contexto de racismo ambiental nos conflitos distributivos.

Para estimular tal noção de Educação Patrimonial Integrada e superar as antigas barreiras natureza $\mathrm{x}$ cultura, sociedade $\mathrm{x}$ meio ambiente $\mathrm{e}$ colonialidades ressaltamos que a participação de diferentes atores capazes de tornarem-se agentes educativos é fundamental para romper a "zona de nãoser"6. A fim de reverter a negação ontológica daqueles colonizados em seus corpos e saberes configura a proposta de giro decolonial a qual buscamos seguir. Insurgindo contra $o$ projeto hegemônico eurocêntrico e sua reivindicação de universalidade, o qual negou a produção material e/ou simbólico das comunidades étnicas reduzindo-as a manifestações animistas e sem qualquer valor estético (ACHINTE, 2013, p.462). De tal modo, estimular ações emancipatórias para as práticas culturais e socioambientais em consonância com abordagem viável para os interlocutores envolvidos.

Por fim, o pensamento de integrar a Educação Ambiental e Educação Patrimonial, sob olhar decolonial, visa caminhar em direção ao emergente campo interdisciplinar de estudos de patrimônio crítico (HARRISON, 2018). Conforme Laurajane Smith (2006) critica o movimento patrimonial voltado apenas para os monumentos e coisas tangíveis, a autora advoga por uma análise crítica de discursos e afetividades. Harrison (2018, p.17) aponta que objetos, lugares e práticas do patrimônio são intervenientes, construindo presentes, compondo mundos e projetando futuros. Neste sentido, o autor aponta para novas perspectivas que iluminam as maneiras pelas quais as coisas e suas dimensões afetivas podem se tornar uma nova área de foco para estudos críticos de patrimônio, explorar conexões importantes entre patrimônio e outras questões contemporâneas de política, preocupação social ou ecológica.

\section{A decolonialidade e a superação da "zona de não-ser": um debate necessário}

Um exemplo de tema abordado de maneira transversal na educação escolar é a "descoberta do Brasil". Assim, no contexto de conquista das Américas, as buscas europeias por terras e recursos causaram impactos devastadores sobre os habitantes destas terras cobiçadas. A colonização foi responsável pela expropriação, expoliação e desapropriação da cultura, do

${ }^{6}$ Zona do não-ser para Fanon (2008) trata-se de uma determinação demarcada pela colonialidade que subjugou a alteridade de peles negras em uma região extraordinariamente estéril e árida.

Revbea, São Paulo, V. 14, № 2: 133-151, 2019.

revista brasileira educação ambiental 
ambiente, das terras e conhecimentos do sul. O poder econômico das grandes nações se construiu a partir de dutos encravados na América Latina, que foram capazes de remover e comercializar os recursos minerais e agrícolas e uma parte da humanidade que foi subjugada a essas mesmas regras (GALEANO, 2011). A opressão sofrida pelos povos ancestrais é imposta até os tempos atuais, onde a relação colonial tomou outros formatos, com novos projetos civilizatórios que envolvem a dominação da educação, meio ambiente e cultura.

Como trata Aimé Césaire, referência nos estudos críticos aos processos coloniais, a relação entre colonizador e colonizado é de trabalho forçado; intimidação; pressão; policial; tributária; furto; violação; imposição cultural; desprezo; desconfiança; necrotério; presunção; grosseria; onde elites são exacerbadas e o povo aviltado. Inexistindo perspectiva humanitária, em seu lugar impera dominação e submissão que transforma o homem colonizado em instrumento de produção (CÉSAIRE, 2006, p.20).

O papel do colonizador, o que tem as certezas, as respostas e as perguntas, é soberano em si mesmo. Define as regras do jogo e o jogo. Individualiza, particulariza, oprime com seu poder para conquistar o território e recomeçar da própria fonte do poder. Disputa as palavras, superficializa ou profundiza conceitos quando convém. O conhecimento se transforma a partir da perspectiva do colonizador. A integração colonizador-colonizado ocorre a partir da sucção do saber, pois ao expropriá-lo cria um novo conhecimento de nível superior na hierarquia dos saberes, mesmo bebendo em fontes locais, populares e ancestrais. A interlocução se dá em nome de um objetivo maior, colonizar, impor uma nova cultura, uma dominação com interesses claros.

Mover o tempo e o espaço se torna necessário para colonizar, torná-los fluidos. Esquecer a história local, os princípios e relações estabelecidas com a terra, garantindo a falta de conhecimento. O novo conhecimento deve ser aprendido, prontamente, para que um mundo melhor se estabeleça. A admiração do colonizado pelo colonizador, a entrega - de corpo, alma e posses- àquele que olha de cima e daí fortalece sua posição, recebendo e nada deixando. Extraindo e usurpando, em uma relação clássica do oprimido e opressor, onde o que é desfavorecido possui uma idolatria cega por quem lhe toma. Não um pensamento ingênuo, puro e selvagem, sim um pensamento alienado, construído do topo, com esse objetivo.

O olhar do colonizador para o colonizado selvagem é de não-admiração, optando por caracterizá-lo por sua "extraodinária deficiência". Muitas vezes, pois, parece se surpreender quando, com seu olhar de pena, observa no carente um comportamento próximo ao seu, civilizado. Neste retrato, o colonizado nunca tem revelada uma imagem positiva, se mantém como um negativo, como descrito por Memmi (1969). 
Como haveria uma reação deste (colonizado), confrontado constantemente com esta imagem de si mesmo, proposta, imposta tanto nas instituições quanto em todo contato humano? Essa imagem não pode deixá-lo indiferente como se estivesse em uma chapa com ela desde o exterior, como se fosse um insulto que voa com o vento. Termina por reconhecê-la, como se fosse um apelido aborrecido, mas convertido em um signo familiar. A acusação o perturba, o inquieta, tanto mais quanto admira e teme ao seu poderoso acusador. Não teria esse um pouco de razão? Murmura. Não seremos a pesar de tudo, nós um pouco culpados? Preguiçosos, posto que temos tantos desocupados? Temerosos, posto que nos deixamos oprimir? Esse retrato mítico e degradante, querido e difundido pelo colonizador, termina por ser aceito e vivido em certa medida pelo colonizado. Adquire deste modo certa realidade e contribui ao retrato real do colonizado (MEMMI, 1969, p.98).

O colonizador retira o direito de liberdade do colonizado. Explora a natureza, leva os seus patrimônios e não deixa quase nada, mantendo a relação histórica de escravidão. Aos colonizados sobra sua vida, mas que vida? O quanto dela não é uma influência direta desse pensamento colonizador? Sua cultura de resistência e a compreensão de que é explorado são caminhos possíveis? Como um ato colonizador influencia na cultura de um lado e de outro do jogo? A desumanização do colonizador e a coisificação do colonizado transformam-se em marcas deste processo. A colonização suprime a possibilidade de participação diante das decisões que contribuem para 0 destino do mundo e do seu próprio, toda responsabilidade histórica e social é retirada do colonizado. Isto porque o mito colonial está apoiado por uma organização real, administrativa e jurídica as quais apoiam as exigências históricas, econômicas e culturais do colonizador, como os baixos salários, destruição de sua cultura e das leis que o regem (MEMMI, 1969).

Refletindo sobre emaranhamentos, Hodder (2012) aponta que os seres humanos dependem das coisas a fim de construir, manter e justificar o poder, dependendo, portanto, das coisas para controlar os outros. Assim, o poder faz uso dos fluxos de significados nas coisas, suas associações e relacionamentos. A perspectiva fornecida pelo emaranhamento desses aspectos é que tais relações de poder não são apenas sobre o controle dos meios de produção, ou o controle das relações sociais ou ideologias sociais. De tal maneira, o papel do colonizador na transformação de visões de mundo adestra a forma de enxergar o outro. Neste contexto, Hodder (2016, pp.64-76) aborda que as relações de emaranhamento constituídas no processo colonizador criam armadilhas, sendo a pobreza um exemplo das armadilhas do emaranhamento.

De acordo com essa abordagem, os grupos subordinados estão presos em um duplo vínculo, dominados por grupos poderosos e indivíduos aprisionados em numerosos emaranhamentos sobrepostos, incluindo baixa 
renda, saúde precária, educação limitada e barreiras burocráticas (HODDER, 2016). Assim, poder-se-ia interpretar relações de dependência, pobreza e mesmo racismo ambiental ${ }^{7}$ como formas de representações de materialismos, que revelam, seja, um objetivo colonizador ou uma rede de relações atreladas às respectivas realidades e modos de vida. A discussão de Hodder (2016) traz que este duplo aprisionamento do dominado é, muitas vezes, associada às condições precárias e à pobreza. Assim, a noção de armadilhas da pobreza tem sido amplamente discutida em relação às condições econômicas recentes e contemporâneas. A armadilha da pobreza toma muitas formas, mas o termo é geralmente usado para descrever de alguma forma o mecanismo de espiralamento através do qual as pessoas não podem sair da pobreza.

Há no colonizado um desejo pela reparação de sua situação, uma busca pelas verdadeiras relações humanas, através da reestruturação das instituições, da abolição das categorias colonizadoras. Urge Memmi:

O colonizado necessita suprimir a colonização para viver. Mas para converter-se em homem necessita suprimir o colonizado que chegou a ser. Se o europeu deve aniquilar em si o colonizador, o colonizado deve superar o colonizado. A liquidação da colonização não é senão um prelúdio da sua liberação completa: a sua autorreconquista. Para libertar-se da colonização foi preciso partir de sua mesma opressão, das carências de seu grupo. Para que sua libertação seja completa, é necessário que se liberte dessas condições, certamente inevitáveis em sua luta. (MEMMI, 1969, p.148).

Em tal processo de desalienação e de reconhecimento de seus conhecimentos ancestrais, integrais, não disciplinarizados, os saberes da terra, das plantas e suas propriedades, a valorização dos laços coletivos sociais, o trabalho com uma relação justa com a natureza e o respeito à diversidade e a diferença devem ser valorizados. $O$ ato de colonizar impõe uma invasão que só pode ser negada pelo oprimido. A liberação não será regalada pelos que detém o poder, pelo contrário, esses se utilizarão de estratégias cordiais, tratados, leis e violência para não perderem seus tronos. Nesse contexto colonial o oprimido tem cor, gênero e raça: são negros, mulheres, indígenas e pobres, os expoliados, desterritorializados e desapropriados. As comunidades latinoamericanas e africanas colonizadas perdem suas raízes e direitos em nome de um desenvolvimento para todos e com a sua luta estão os conhecimentos pós-coloniais que devem ser apreendidos em busca da transformação social. Seguindo Fanon (2008):

${ }^{7}$ Herculano e Pacheco (2006, p.16) discursam sobre racismo ambiental e justiça socioambiental como desigualdade e injustiça que recaem sobre etnias e comunidades locais.

Revbea, São Paulo, V. 14, № 2: 133-151, 2019. 
A Sociedade, ao contrário dos processos bioquímicos, não escapa à influência humana. É pelo homem que a Sociedade chega ao ser. O prognóstico está nas mãos daqueles que quiserem sacudir as raízes contaminadas do edifício. (...) de uma vez por todas, a realidade exige uma compreensão total. No plano objetivo como no plano subjetivo, uma solução deve ser encontrada. E é inútil vir com ares de mea culpa, proclamando que o que importa é salvar a alma. Só haverá uma autêntica desalienação na medida em que as coisas, no sentido o mais materialista, tenham tomado os seus devidos lugares (FANON, 2008, pp.28-29).

Para se libertar do arsenal de complexos germinados no seio da situação colonial tais reflexões apontam caminhos que educam para além dos limites estruturados pela sociedade, no reconhecimento da ciência europeia moderna colonial como promotora de formas de vida que buscam uma unidade, uma globalização encobrindo outro. Existe, a partir daí, uma construção de linguagem e território que coloca o colonizado à margem. Assim sendo, "A liberdade de um relaciona-se com extrapolar a resistência do outro, ir além, se formar nesse processo e ter a autonomia como resposta para o que está posto" (FANON, 2008,p.27). O conhecimento para a desalienação tem em sua base saberes que promovam respeito a igualdade e a diversidade de gênero, de raça e social.

Catherine Walsh (2017, p.18) critica as ações do vigente projeto "capitalista-modernizador-extrativista" que desapropria e destrói modos de vida, caminhando juntamente com a lógica "patriarcal-paternal-colonial" e a criminalização do protesto, a crescente violência e repressão de jovens e mulheres, bem como o silenciamento do pensar criticamente. Dessa maneira, a construção de propostas de educação decolonial soa como os gritos, as esperanças e as forças que se juntam caminhando. Mostrando neste encontro que não estamos sozinhos e que não somos poucos (WALSH, 2017, p.43). Nesse encontro para pensar criticamente através da Educação Ambiental e Patrimonial compreendemos que 0 ato de valorizar as comunidades locais, desvelando suas raízes históricas culturais e ambientais, pode auxiliar a emancipá-las em busca de outros modos-práticas.

Nesse encontro para pensar criticamente através da Educação Ambiental e patrimonial compreendemos que 0 ato de deslindar as raízes históricas culturais e ambientais das comunidades vulnerabilizadas pelo racismo ambiental, pode fazer emergir conhecimentos formados a partir de perspectivas outras e que caminham em busca de outros modos-práticas. A partir do exposto, pode-se perceber que o conceito de racismo ambiental problematizado nas escolas é certamente um aspecto relevante para a intermulti-transdisciplinaridade na articulação crítica entre a Educação Ambiental e Educação Patrimonial, numa perspectiva pedagógica decolonial. Neste contexto, destacamos a necessidade de uma abordagem holística dos 
conhecimentos de matriz africana, das comunidades tradicionais, dos povos indígenas e das populações em vulnerabilidade socioambiental da América Latina, como saberes que se posicionam frente ao avassalador modelo de conhecimento hegemônico do mundo moderno, para sentipensar o campo do etnoconhecimento em oposição à noção de modernidade/racionalidade (QUIJANO, 1992) para questionar o etnocídio e romper com a dimensão ontológica da colonialidade do ser, do saber, do poder e da natureza (FANON, 2008; WALSH, 2006; WALSH, 2014).

\section{Considerações finais: perspectivas para atuação}

Este é um trabalho teórico que buscou demonstrar conexões entre as perspectivas críticas de Educação Ambiental e Patrimonial com proposta de seguir o giro decolonial. A abordagem de Educação Patrimonial e da Educação Ambiental como forma de compreensão sócio histórica das referências culturais e ambientais em todas as suas manifestações do saber. Conhecimentos que contribuem no enfrentamento junto às lutas sociais dos oprimidos, colaboram para seu reconhecimento, valorização e preservação. A educação posicionada diante do quadro de opressão colonial faz parte da visão ampliada provocada pelo enfrentamento das injustiças que recaem sobre os colonizados. O diálogo inicial proposto busca contribuir para o reconhecimento do sistema de produção de conhecimento hegemônico em contraponto à transversalidade dos saberes de povos e comunidades vulnerabilizadas. Apontando o racismo ambiental como intercessão das opressões identificadas no campo da Justiça Ambiental pelas perspectivas críticas da Educação Ambiental e Patrimonial.

Se a perspectiva crítica no campo da Educação Ambiental pode revelar visões de mundo distintas do discurso conservador colonial ocidental, a atuação no eixo da Educação Patrimonial pode aprofundar conhecimentos sobre noções e relações de emaranhamento entre humanos-coisas. A partir de um panorama de teias de emaranhamento, uma vez que os nódulos e teias sobrepostas revelam tessituras sobre aspectos que podem ser trabalhados sob a ótica de debates em patrimônio material/imaterial e em Educação Ambiental. $\mathrm{Na}$ busca de uma ciência crítica ao processo colonial que se proponha a romper com a colonização do poder, do ser, do saber da natureza, este trabalho trata de investigar rumos mais conectados entre as formas de construir saberes coletivamente e entre campos de conhecimento diversos que se complementam.

Desse modo, a construção, valorização, difusão e preservação de conhecimentos devem estar aliadas à sustentabilidade e viabilidade para interlocutores de pesquisa. Uma equipe multidisciplinar faz-se necessária para reconhecer aspectos referentes aos processos capazes de instrumentalizar os indivíduos fazer a leitura do mundo que o rodeia mirando para romper com a zona do não-ser ao realizar a virada proposta pela decolonialidade. Por fim, ratificamos que buscamos aqui apresentar possíveis caminhos teóricos para 
aplicar os estudos decoloniais à Educação Ambiental Crítica junto à Educação Patrimonial e novas perspectivas no campo de estudo de patrimônio crítico. Uma proposta que busca romper com os padrões estabelecidos na relação colonizado x colonizador constitui-se na negação da legitimidade de conhecimentos que operam nas relações socioambientais que se dão a partir da expropriação e dominação da natureza, do saber e do ser.

\section{Agradecimentos}

O presente trabalho foi realizado com apoio da Coordenação de Aperfeiçoamento de Pessoal de Nível Superior (CAPES) - Código de Financiamento 001, segundo a portaria 206, de 04 de setembro de 2018 concedido aos dois primeiros autores deste artigo. Agradecemos aos revisores da revista, que de modo profícuo colaboraram para o debate ser ampliado de forma clara. Ao Programa de Pós-Graduação em Educação da UNIRIO que proporcionou o encontro dos autores deste artigo e demais debates junto ao Grupo de Estudos em Educação Ambiental desde el Sur (GEASur). Às leituras atenciosas de Cândido Rafael Mendes e Armando de Melo Lisboa que contribuíram com sugestões mais do que pertinentes para construção desta escrita.

\section{Referências Bibliográficas}

ABRAMOVAY, M. Violências na escola. Brasília: UNESCO, 2002. p. 281-291. ACHINTE, A.A. Pedagogías de la Re-Existencia. Artistas indígenas y afrocolombianos. In: WALSH, C. Pedagogías decoloniales. Prácticas insurgentes de resisitir, (re) existir y (re)vivir. Tomo I. Serie Pensamiento Decolonial. Quito: Abya Yala. 2013, p. 443-468

AQUINO, C.V. Educação Patrimonial na sala de aula: a escola como patrimônio cultural. Educação Patrimonial: Diálogos entre escola, museu e cidade. Caderno Temático 4. IPHAN: Casa do Patrimônio da Paraíba. 2015. p. 25-31.

CARVALHO, I.C.M. Educação Ambiental Crítica: nomes e endereçamentos da educação. In: Identidades da educação ambiental brasileira. Brasília: Ministério do Meio Ambiente. 2004. p. 13-24.

CÉSAIRE, A. Discurso sobre el colonialismo. Madrid: Akal. 2006.

CLASTRES, P. Arqueología de la violencia. Fondo de Cultura Economica USA. 2004.

DESCARTES, R. Discurso do Método. São Paulo: Escala. 2005.

EVARISTO, J.A. Um estudo sobre educação ambiental proposta no pcn. Monografia de Pedagogia. Universidade Estadual de Londrina. 2010.

FANON, F. Pele negra, máscaras brancas. Bahia: Editora Edufba. 2008. 
FREIRE, P. Pedagogia do Oprimido. Rio de Janeiro: Paz \& Terra. 1969.

FUNARI, P.P. Public archaeology from a Latin American perspective. Public Archaeology. Vol. (1):239-243. 2001.

FUNARI, P.P.; PELEGRINI, S.C. A. Patrimônio histórico e cultural. Rio de Janeiro: Jorge Zahar Ed. 2006. 72 p.

GALEANO, E. As Veias Abertas da América Latina. Porto Alegre: L\&PM Pocket. 2011.

GEERTZ, C. A interpretação das culturas. Rio de Janeiro: Guanabara/Koogan. 1991.

GUIMARÃES, M. Educação Ambiental Crítica. In: LAYRARGUES, P.P. (Org.). Identidades da educação ambiental brasileira. Brasília: Ministério do Meio Ambiente. 2004. p. 25-34.

HARRISON, R. On Heritage Ontologies: Rethinking the Material Worlds of Heritage. Anthropological Quarterly, v. 91, n. 4. 2018. p. 1365-1383.

HERCULANO, S.; PACHECO, T. (Org.). Racismo Ambiental - I Seminário Brasileiro contra o Racismo Ambiental. Rio de Janeiro: Fase. 2006. 331p.

HODDER, I. Entangled: An archaeology of the relationships between humans and things. John Wiley \& Sons. 2012.

HODDER, I. Studies in Human-Thing Entanglement. Open access book. 2016.

HORTA, M.L.P.; GRUNBERG, E.; MONTEIRO, A.Q. Guia básico de educação patrimonial. Brasília: IPHAN: Museu Imperial, 1999.

INGOLD, T. Humanidade e animalidade. Revista Brasileira de Ciências Sociais. V.28, p.39-53. 1995.

LAYRARGUES, P.P. Identidades da educação ambiental brasileira. Ministério do Meio Ambiente / Diretoria de Educação Ambiental. Brasília: Ministério do Meio Ambiente. 2004.

LÉVI-STRAUSS, C. Natureza e cultura. As estruturas elementares do parentesco. 1982.

LOUREIRO, C.F.B. Educação ambiental e epistemologia crítica. REMEA, Rio Grande, v. 32, n. 2, 2015, p. 159-176. Disponível em: <https://www.seer.furg.br/ remea/article/ view/5536/3443 >. Acesso em: 29 abr. 2018.

LOUREIRO, C.F.B. A questão ambiental no pensamento crítico: natureza, trabalho e educação. 1르. Ed. Rio de Janeiro: Quartet. 2007.

LOUREIRO, C.F.B. Complexidade e dialética: contribuições à práxis política e emancipatória em educação ambiental. Educação e Sociedade, V.27, n.94, p.131-152, 2006. 
LOUREIRO, C.F.B. Educação Ambiental Transformadora. In: LAYRARGUES, P.P. (Org.). Identidades da educação ambiental brasileira. Brasília: MMA, 2004.

MEMMI, A. Retrato del Colonizado. Buenos Aires. Ediciones de la Flor. 1969.

MORIN, E. O paradigma perdido: A natureza humana. Lisboa: Publicações Europa-América. 1973.

MUNIZ, T.S.A. Pesquisa-Ação Em Uma Escola Sócio-Construtivista: As Relações Humano-Natureza No Ensino De Ciências. Revista Sustinere. Vol. 4 n.2, p. 187-220, 2016. Disponível em: <http://www.epublicacoes.uerj.br/index.php/ sustinere/article/view/24977> Acesso em: 02/02/2017.

PACHECO, I.A.; VARGAS, I. Albuquerque de. Educação patrimonial: um recurso para alfabetização cultural no ensino fundamental. Ateliê Geográfico. Goiânia-GO. V.3 N.1. Abril. 2009. p. 92-106.

PELEGRINI, S.C.A. Patrimônio cultural: consciência e preservação. São Paulo: Brasiliense, 2009.

QUIJANO, A. Colonialidad y Modernidad-racionalidad. In: BONILLO, Heraclio. Los conquistados. Bogotá: Tercer Mundo Ediciones; FLACSO. 1992.

REIGOTA, M. O que é educação ambiental? Brasiliense, São Paulo, Brasil. 1991.

SMITH, L. Uses of Heritage. Abingdon: Routledge. 2006.

SOUZA, R.C. Guia básico de educação patrimonial: referência nos arquivos digitais. VI Colóquio Internacional: Educação e Contemporaneidade. São Cristóvão-SE. 2012.

WALSH, C.E. Lo pedagógico y lo decolonial: Entretejiendo caminhos. Colec vo Zapateándole al mal gobierno, 2014

WALSH, C.E., ed. Pedagogías decoloniales: prácticas insurgentes de resistir,(re) existir y (re) vivir. Tomo II. Serie Pensamiento Decolonial. Quito: Abya Yala. 2017.

WEIL, P. Rumo à nova transdisciplinaridade. Summus Editorial. 1993. 